\title{
Cells and mediators of inflammation (C-reactive protein, nitric oxide, platelets and neutrophils) in the acute and convalescent phases of uncomplicated Plasmodium vivax and Plasmodium falciparum infection
}

\author{
Josué da Costa Lima-Junior ${ }^{1,2}$, Rodrigo Nunes Rodrigues-da-Silva', Virgínia Araújo Pereira1, \\ Fábio Luiz Storer ${ }^{3}$, Daiana de Souza Perce-da-Silva ${ }^{4}$, Daniela Leite Fabrino ${ }^{5}$, \\ Fátima Santos ${ }^{6}$, Dalma Maria Banic ${ }^{5}$, Joseli de Oliveira-Ferreira ${ }^{1 /+}$ \\ ${ }^{1}$ Laboratório de Imunoparasitologia ${ }^{5}$ Laboratório de Simulídeos e Oncocercose, Instituto Oswaldo Cruz \\ ${ }^{2}$ Centro de Desenvolvimento Tecnológico em Saúde-Fiocruz, Rio de Janeiro, RJ, Brasil \\ ${ }^{3}$ Faculdade São Lucas, Porto Velho, RO, Brasil ${ }^{4}$ Laboratório de Biotecnologia, Departamento de Química, \\ Biotecnologia e Engenharia de Bioprocessos, Universidade Federal de São João Del Rei, Ouro Branco, MG, Brasil \\ ${ }^{6}$ Departamento de Entomologia, Laboratório Central, Porto Velho, RO, Brasil
}

The haematological changes and release of soluble mediators, particularly C-reactive protein (CRP) and nitric oxide (NO), during uncomplicated malaria have not been well studied, especially in Brazilian areas in which the disease is endemic. Therefore, the present study examined these factors in acute (day 0) and convalescent phase (day 15) patients infected with Plasmodium falciparum and Plasmodium vivax malaria in the Brazilian Amazon. Haematologic parameters were measured using automated cell counting, CRP levels were measured with ELISA and NO plasma levels were measured by the Griess reaction. Our data indicate that individuals with uncomplicated $\mathrm{P}$. vivax and $\mathrm{P}$. falciparum infection presented similar inflammatory profiles with respect to white blood cells, with high band cell production and a considerable degree of thrombocytopaenia during the acute phase of infection. Higher CRP levels were detected in acute $\mathrm{P}$. vivax infection than in acute $\mathrm{P}$. falciparum infection, while higher $N O$ was detected in patients with acute and convalescent $\mathrm{P}$. falciparum infections. Although changes in these mediators cannot predict malaria infection, the haematological aspects associated with malaria infection, especially the roles of platelets and band cells, need to be investigated further.

Key words: malaria - C-reactive protein - nitric oxide - band neutrophils

Haematologic changes, such as anaemia, thrombocytopaenia and leucocytosis or leucopoenia, are well recognised to be associated with malaria infection. The extent of these alterations varies with the level of malaria endemicity, patient genetic background (e.g., presence of haemoglobinopathies), nutritional status, demographic factors and malaria immunity (Price et al. 2001, Erhart et al. 2004). Changes in the total white cell (WC) and platelet (PLT) counts have been documented in several clinical vivax and falciparum malaria cases in immune and naïve patients of all ages (Martelo et al. 1969, Winters \& Murray 1992, Ladhani et al. 2002, Taylor et al. 2008) and the disease is often associated with mild or moderate thrombocytopaenia in adults and children from malariaendemic areas. Profound thrombocytopaenia is unusual and rarely associated with haemorrhagic manifestations (Casals-Pascual et al. 2006). In most clinical studies, thrombocytopaenia is not associated with disease severity or mortality, but the combination of a low PLT count

Financial support: DCIT/CNPq, CAPES

+ Corresponding author: 1ila@ioc.fiocruz.br

Received 30 July 2012

Accepted 14 September 2012 and high density of polymorphonuclear cells indicates a strong inflammatory profile. In this inflammatory milieu, neutrophils are one of the key players in the innate immune system and represent the first line of defence against invading microorganisms, mainly because they are the most numerous blood leucocyte cells (50-75\%) and the most effective circulatory phagocytes. Neutrophils are generated in the bone marrow from myeloid human precursors cells by a highly coordinated differentiation process, which is characterised by significant morphological changes and the up-regulation of signalling pathways and receptors for inflammatory mediators (Mora-Jensen et al. 2011). Consequently, the neutrophil precursor count is also an important indicator of inflammation (Zhu et al. 2010, Corti et al. 2012) and variations in this parameter are routinely measured in the laboratory in malaria endemic areas as a sensitive, but nonspecific indicator of infection with malaria parasites (Maina et al. 2010, Habeeb et al. 2012).

In addition to cytokines and chemokines, other unspecific mediators of inflammation are also biomarkers in malaria infection. Several soluble mediators released during malaria infection, particularly C-reactive protein (CRP) and nitric oxide (NO), were identified as important inflammatory biomarkers (McGuire et al. 1996, Armah et al. 2007, Conroy et al. 2011). In fact, NO and CRP levels have proven to be valuable in assessing the severity of malaria and as prognostic tools in the follow-up re- 
sponse to treatments (Gillespie et al. 1991, Nahrevanian et al. 2008). CRP is believed to play an important role as an early defence system against infection in the body; during acute inflammation, CRP levels increase to as much as 50,000 times above normal, typically within 6 $\mathrm{h}$ and peak at $48 \mathrm{~h}$. The CRP level is an accurate indicator of inflammation and the only known factor to interfere with CRP production is liver failure. CRP is well characterised as a serum acute phase protein and has been shown to be involved in multiple immunoregulatory functions. For example, CRP activates the classical complement cascade, opsonises bacteria for phagocytosis and stimulates phagocytic cells (Dong \& Wright 1996). Although CRP is predominantly produced and secreted by hepatocytes, other cells, including subsets of lymphocytes, Kupffer cells and blood monocytes, have also been shown to synthesise this protein (Dong \& Wright 1996). The first identification of a role for CRP in defence against infection in humans was related to its capacity to bind to phosphorylcholine in membranes of microorganisms (Gotschlich \& Edelman 1967). In malaria, CRP secretion is induced by proinflammatory cytokines that are secreted by host mononuclear cells (Harpaz et al. 1992) and strong correlations have been found between CRP levels and parasitaemias. Meanwhile, NO, which is highly toxic to intra-erythrocytic malaria parasites, seems to be associated with the severity of Plasmodium falciparum malaria. Indeed, the high NO production by neutrophils has been correlated with fast parasite clearance in P. falciparum malaria (Greve et al. 1999), suggesting that the release of nonspecific inflammatory markers might be more important for immune protection from malaria than is generally appreciated.

Although the basic haematologic changes in nonspecific markers of infection and inflammation associated with malaria infections are not recent findings, their contributions during acute uncomplicated malaria and after treatment remain unclear. Furthermore, the diagnostic value of these haematological parameters has not been well established in Brazilian endemic areas, in which more than $80 \%$ of malaria cases are caused by Plasmodium vivax (Oliveira-Ferreira et al. 2010). Therefore, the present study examined the changes in blood PLTs, neutrophils, CRP and NO in adults from the Brazilian Amazon with uncomplicated P. falciparum and $P$. vivax malaria who were followed up during the acute and convalescent phases of infection.

\section{SUBJECTS, MATERIALS AND METHODS}

Study population - The studied population included rainforest natives and migrants from several non-endemic areas of Brazil who resided in the region. Samples and survey data were collected during the dry months of June-August in 2007, coinciding with the period of increased malaria transmission in the state of Rondônia. The individuals who sought malaria diagnosis at the Polyclinic Ana Adelaide outpatient clinic in Porto Velho and tested positive by thick blood smear were formally invited to participate in our study. A total of 71 symptomatic malaria patients were enrolled and blood samples were collected on the day of diagnosis before treatment (acute phase) and 15 days later (convalescent phase). Of the 71 initially enrolled patients, 55 returned for the 15-day follow-up. The patients were grouped by plasmodial species: $P$. vivax $(\mathrm{n}=47)$ and $P$. falciparum $(\mathrm{n}=24)$. Written informed consent was obtained from all adult donors or from the parents of underage donors. The study was reviewed and approved by the Oswaldo Cruz Foundation Ethical Committee and the National Ethical Committee of Brazil.

Clinical and epidemiological survey - To evaluate the epidemiological factors that may influence the variations in the inflammatory markers studied and the symptoms, all donors were interviewed after providing informed consent. The survey included questions related to demographics, time of residence in the endemic area, personal and family histories of malaria, use of malaria prophylaxis, presence of malaria symptoms and personal knowledge of malaria. The survey data were entered into a database created with Epi Info 2007 (Centers for Disease Control and Prevention, Atlanta, GA, USA).

Collection of human blood samples and malaria diagnosis - Venous peripheral blood $(10 \mathrm{~mL})$ was collected into ethylenediamine tetraacetic acid tubes. Thin and thick blood smears from all donors were examined for malaria parasites at 1,000X magnification under oil immersion; all slides were examined by two researchers with expertise in malaria diagnosis. Donors who were positive for $P$. vivax and/or $P$. falciparum were subsequently treated with the chemotherapeutic regimen recommended by the Brazilian Ministry of Health. To confirm the parasitological diagnosis (day 0) and parasite clearance (day 15), we performed molecular analyses of all samples using primers specific for genus (Plasmodium sp.) and species (P. falciparum and P. vivax). The amplification protocols were described previously (Snounou et al. 1993).

PLT and neutrophil counts - Complete blood counts were performed using an automatic haematology analyser (ABX Pentra) and peripheral smears of blood samples were made for routine differential blood cellular quantification. A manual differential WC count was also performed to distinguish the immature neutrophils. Neutropaenia was defined as a neutrophil count $<1.20 \times 10^{9} / \mathrm{L}$ and thrombocytopaenia was defined as a PLT count $<$ $150 \times 10^{9} / \mathrm{L}$.

CRP levels - The CRP levels were determined in all plasma samples using an in-house ELISA. Microtitre plates (Nunc/MaxiSorp, Rochester, NY, USA) were coated with a goat anti-human-CRP antibody (Sigma, USA; catalogue C8284) in carbonate-bicarbonate buffer $\left(\mathrm{TCO}_{4}\right)$ overnight at $4^{\circ} \mathrm{C}$. The plates were then washed three times with phosphate-buffered saline- $0.05 \%$ Tween 20 (PBST) and plasma samples diluted 1:500 in PBST were incubated with the plates for $1 \mathrm{~h}$ at $37^{\circ} \mathrm{C}$. The plates were then washed three times and incubated with rabbit anti-human-CRP antibody (Sigma, USA; catalogue C3527) in PBST for $1 \mathrm{~h}$ at $37^{\circ} \mathrm{C}$. The plates were washed three times and peroxidase-conjugated goat antirabbit-IgG antibodies (Sigma, USA; A0545) were added. 
The wells were thoroughly washed to remove all unbound horseradish peroxidase (HRP)-conjugated antibodies and an o-phenylendyamine substrate solution was added to each well. The enzyme (HRP) and substrate were allowed to react for a short incubation period. The enzyme-substrate reaction was terminated by the addition of $2 \mathrm{~N} \mathrm{H}_{2} \mathrm{SO}_{4}$ and the degree of colour change was measured at $492 \mathrm{~nm} \pm 2 \mathrm{~nm}$ in a spectrophotometer (SpectraMax 250; Molecular Devices, Sunnyvale, CA). The plasma concentration of CRP was determined by comparison to standard concentrations of purified human CRP (Sigma, St. Louis, USA). The range of detection of CRP was $0.01-320 \mu \mathrm{g} / \mathrm{mL}$. Sera from non-infected individuals were used on every plate as negative controls. Specific CRP optical density values were converted to concentration values $(\mu \mathrm{g} / \mathrm{mL})$ using sigmoidal curve-fit equations derived from CRP standard curves.

Griess microassay detection of NO - A modified Griess reaction was used to detect NO (Rockett et al. 1994, modified by Nahrevanian \& Dascombe 2001). The NO levels in samples were indirectly measured after first converting nitrates to nitrites with a nitrate reductase treatment (Aspergillus species NAD $[\mathrm{P}] \mathrm{H}$, Sigma, UK) and NADPH $\beta$-nicotinamide adenine dinucleotide phosphate (Sigma Diagnostics, St. Louis, USA). Griess reagent [5\% phosphoric acid, $1 \%$ sulphanilic acid and $0.1 \%$ $\mathrm{N}$-(1-naphthyl-1)-ethylendiamine dihydrochloride, all from Sigma, UK, dissolved in $100 \mathrm{~mL}$ deionised water] was added and proteins were subsequently precipitated by trichloroacetic acid (BDH, England). The tube contents were mixed and centrifuged (Eppendorf centrifuge $5415 \mathrm{C}$, Germany); two samples of each supernatant were transferred to a flat-bottomed microplate and their absorbencies were read at $520 \mathrm{~nm}$ using a microplate reader (SpectraMax, Molecular Devices Inc). NO values were calculated from standard calibration plots (Nahrevanian \& Dascombe 2001).

\section{RESULTS}

Epidemiological and clinical characteristics of the studied population - The mean age, length of time living in the endemic area, number of previous malaria infections and parasite density were similar between the $P$. vivax and $P$. falciparum malaria patient groups (Table). There were no significant differences in the general features of malaria exposure in the patient groups and malaria-endemic control group (group C), except for the number of months since the last malaria episode $(\mathrm{p}<$ 0.0001 ). All patients in the acute phase of infection (day $0)$ presented symptomatic noncomplicated malaria. Fever and headache were the most frequent symptoms reported by patients infected with either parasite, indicating that the plasmodial species did not show differences in the clinical manifestation of disease ( $p>0.05$ for all reported symptoms). Among the patients who returned at day $15,87.5 \%$ had been diagnosed with $P$. vivax at day 0 and $62 \%$ had been diagnosed with $P$. falciparum. At day 15 , no patients presented with symptoms and no parasites were detected by microscopic examination or polymerase chain reaction.
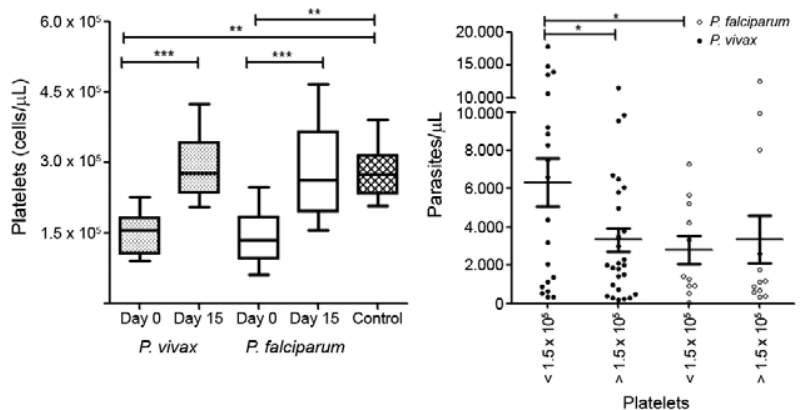

Fig. 1A: platelets concentration in plasma of studied individuals during acute and convalescent phase of malaria infection (box represent the interquartile range and whiskers represents the 95 percentiles); B: scatter dot plot of parasitaemia in infected individuals with and without thrombocytopaenia.

PLTS - The PLT counts were significantly lower in the acute phase of malaria infection than in the convalescent phase [day $0 v s$. day $15 ; \mathrm{t}=10.74$, degrees of freedom $=54, p<0.001]$ or in the control group $(\mathrm{p}<0.0001)$. Indeed, thrombocytopaenia (less than 150,000 PLTs/ $\mathrm{mm}^{3}$ ) was observed in $44 \%$ of studied individuals in the acute phase, regardless of Plasmodium species ( $47 \%$ for $P$. falciparum and $42.6 \%$ for $P$. vivax). After treatment, the mean PLT levels returned to normal $\left(292,208 / \mathrm{mm}^{3}\right)$, with levels similar to that of the control group (Fig. 1). The PLT number did not correlate with any epidemiological or clinical parameter evaluated in our survey; however, the mean parasitaemia of individuals who presented thrombocytopaenia $(5,077$ parasites $/ \mathrm{mL})$ was significantly higher than in individuals without thrombocytopaenia $(3,331$ parasites $/ \mathrm{mL} ; \mathrm{t}=2.271, \mathrm{p}=0.0422)$. Interestingly, this phenomenon was observed only in $P$. vivax -infected individuals $(6,328$ vs. 3,326 parasites $/ \mathrm{mL}$; $\mathrm{t}=2.297, \mathrm{p}=0.0263)$ and not in $P$. falciparum-infected individuals (2802 vs. 3343; $\mathrm{t}=0.3659, \mathrm{p}=0.8171)$.

Neutrophil and band cell variations in the acute and convalescent phases of malaria - The mean neutrophil count in the control group $(3.825 \pm 1.081)$ was similar to the acute $(3.503 \pm 1.515 ; \mathrm{p}=0.3350)$ and convalescent phases $(3.035 \pm 1.433 ; p=0.3111)$. The absolute number of neutrophils was not correlated with any epidemiological factor, but it was inversely correlated with parasitaemia in both $P$. falciparum and $P$. vivax-infected individuals $(\mathrm{r}=$ $-0.284, \mathrm{p}=0.017$, respectively). Interestingly, $71 \%$ of the studied individuals presented high numbers of band cells (immature neutrophils). Indeed, the absolute number of band neutrophils was markedly high in the acute phases of the $P$. vivax $(207.2 \pm 326.4 / \mu \mathrm{L})$ and $P$. falciparum $(284.1 \pm$ $390.0 / \mu \mathrm{L}$ ) groups; in the convalescent phase, the band cell number returned to a level similar to that of the control group $(12.1 \pm 28.0 / \mu \mathrm{L})$ (Fig. 2B). The number of band cells was not correlated with parasitaemia in the acute phase. However, band cell number was inversely correlated with the number of previous malaria infections $(\mathrm{r}=-0.258 ; \mathrm{p}=$ 0.0310 ) and directly correlated with the number of months since the last malaria infection $(r=0.265 ; \mathrm{p}=0.039)$. 

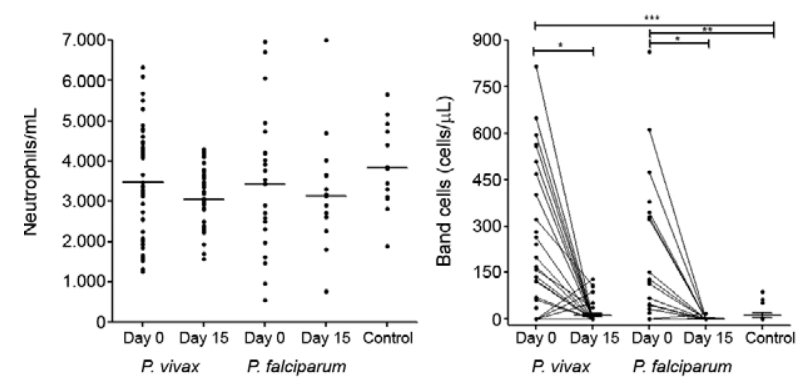

Fig. 2A: neutrophil count of studied individuals during acute and convalescent phase of malaria infection; B: variations in band neutrophil count during acute phase of malaria infection (day 0 ) and convalescent phase (day 15) indicate a significantly higher band neutrophil count in acute phase of Plasmodium vivax and Plasmodium falciparum infection.

$C R P$ - During the acute phase, an increased concentration of CRP was observed in $87 \%$ of studied individuals compared to the control group (cut-off $=$ mean + 3 standard deviation). The overall mean concentration during the acute phase of infection (day 0) was 27-times higher $(27.82 \pm 30.94 \mu \mathrm{g} / \mathrm{mL})$ than that in the control group $(2.2 \pm 4.49 \mu \mathrm{g} / \mathrm{mL}, \mathrm{p}<0.0001)$, whereas in the convalescent phase (day 15), the CRP concentration dropped to basal levels $(3.0 \pm 2.53 \mu \mathrm{g} / \mathrm{mL})(\mathrm{p}<0.0001)$ comparable to those of the control group $(\mathrm{p}=0.826)$ (Fig. 3A). Interestingly, acute phase CRP levels were also higher in $P$. vivax patients (mean \pm standard error of the means; $30.56 \pm 4.5 \mu \mathrm{g} / \mathrm{mL}$ ) than in P. falciparum patients $(18.2 \pm 4.5 \mu \mathrm{g} / \mathrm{mL} ; \mathrm{p}=0.0273)$. However, CRP levels were not correlated with any of the clinical or epidemiological factors considered in our analysis.

$N O$ - The overall median levels of plasma nitrite in the acute phase were significantly higher in $P$. falciparum-infected individuals $(7.01 \pm 5.90 \mu \mathrm{M})$ than in $P$. vivax-infected individuals $(3.1 \pm 2.4 \mu \mathrm{M} ; \mathrm{p}=0.0014)$ or the control group $(2.99 \pm 2.60 \mu \mathrm{M} ; \mathrm{p}=0.0292)$. No differences in the nitrite levels of all groups were observed between the convalescent phase and acute phase. However, the levels were higher in the P. falciparum group than the $P$. vivax $(\mathrm{p}=0.0003)$ and control $(\mathrm{p}=0.0029)$ groups. We did not observe any correlation between the nitrite plasma levels and symptoms, number of past malaria episodes, time of residence in the endemic area or number of months since the last malaria infection. However, the serum nitrite concentration was inversely correlated with the number of malaria infections in the past six months $(r=-0.390 p=0.030)$.

\section{DISCUSSION}

In the present work, we detected classical inflammatory biomarkers (cells and mediators) in uncomplicated malaria patients infected with $P$. falciparum or $P$. vivax during the acute (day 0 ) and convalescent phases (day 15). In our cohort, the $P$. vivax and $P$. falciparum groups were comparable in gender, age, time of malaria exposure and number of past malaria infections. The cohort included rainforest region natives and transmigrants from non-endemic areas of Brazil who had lived in the region for more than 10 years and the majority of studied individuals reported a prior experience with $P$. vivax or $P$. falciparum malaria. All patients presented uncomplicated malaria and exhibited general clinical symptoms, such as a history of fever and headache, regardless of the Plasmodium species detected. Indeed, our control group, which was composed of exposed individuals who reported no malaria episodes in the last five years, was similar to the infected cohorts. The selection of these individuals as controls was ideal to distinguish whether the alterations found in cells and mediators were related to malaria infection or the social and health conditions of the native Amazon population.

Malaria is a complex multi-system disorder involving several inflammatory mediators. Monocytes, macrophages, endothelial cells, neutrophils and PLTs all express pattern recognition receptors, primarily toll-like receptors (Akira \& Takeda 2004). Of these, PLTs and neutrophils are the most numerous, mobile and likely to encounter merozoites and parasite-altered erythrocytes early in infection. Therefore, one of the haematological hallmarks of acute malaria is thrombocytopaenia. Despite the infrequent occurrence of severe bleeding in severe malaria or co-infection (Abbasi et al. 2009), malaria-related thrombocytopaenia is usually observed at frequencies ranging
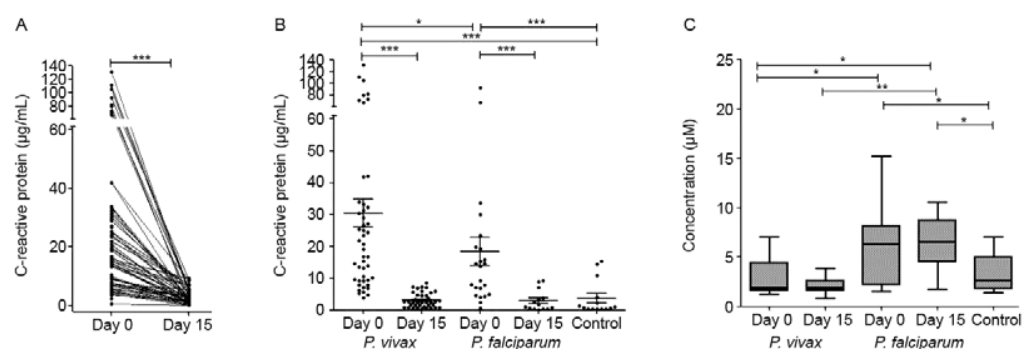

Fig. 3A: concentration of C-reactive protein (CRP) in plasma of all studied individuals during acute and convalescent phase of malaria infection; B: in scatter dot plot of CRP concentration in Plasmodium vivax and Plasmodium falciparum infected individuals we observed significantly higher mean of CRP levels (line) were observed in P. vivax infected individuals when compared with P. falciparum; C: nitric oxide concentrations in plasma of studied individuals during acute and convalescent phase of malaria infection (box represent the interquartile range and whiskers represents the 95 percentiles). 
from 24-94\% (Lacerda et al. 2011). Moreover, it is unclear whether this haematological complication is more frequent in $P$. vivax or $P$. falciparum malaria. In our study, low PLT counts were present in a large portion of acute phase patients independent of the plasmodial species, but PLTs returned to basal levels in the convalescent phase. Among $P$. vivax-infected individuals, parasitaemia was significantly higher in individuals with confirmed thrombocytopaenia than in non-thrombocytopaenic individuals. The trend of decreasing PLT count with increasing levels of parasitaemia observed in this study has been extensively described in P. falciparum over the past several decades (Perrin et al. 1982, Rojanasthien et al. 1992, Richards et al. 1998), but it is less documented in the literature for P. vivax (Erhart et al. 2004). Thrombocytopaenia in noncomplicated malaria appears to be immune mediated; the immune complexes circulating in malaria-infected patients may play a role in the peripheral destruction of PLTs and RBCs. Indeed, the phagocytosis of PLTs has also been reported in malaria patients. However, electron microscopy analyses have also demonstrated a direct interaction between plasmodium and PLTs in patients with malaria (McMorran et al. 2009).

Several reports indicate that neutrophils may be involved in the early control of blood parasites (Appelberg 2007). The activation of neutrophils in the initial stages of malaria infection is well supported (Graca-Souza et al. 2002, Mohammed et al. 2003) and transcriptome analyses of whole blood from humans infected with $P$. falciparum also revealed a unique gene expression profile related to neutrophil activity during early infection (Griffiths et al. 2005). Although low neutrophil count has been linked with acute $P$. falciparum malaria (Ladhani et al. 2002) and the contributions of neutrophils to host defence have been long investigated (Brown \& Smalley 1981, Kharazmi \& Jepsen 1984), their roles in uncomplicated ( $P$. vivax and $P$. falciparum) malaria remain unclear. Our data indicate that malaria-infected individuals had neither an increased frequency of neutropaenia nor a low neutrophil count relative to the control group. However, the high band neutrophil count observed in the acute phase of infection and the return to normal levels in the convalescent phase suggest an accelerated production and/or release of neutrophils during malaria infection. Indeed, the inverse correlation of band count with the number of past malaria infections and the direct correlation of band count with the number of months since the last malaria infection suggest that less exposed individuals respond to parasite stimulus with a greater inflammatory profile and, consequently, increased neutrophil production.

Therefore, to evaluate the inflammatory profile associated with uncomplicated malaria infections, we investigated the plasma levels of two inflammatory mediators, CRP and NO, in patients with $P$. falciparum and $P$. vivax infections. As expected, we observed high levels of CRP in the acute phase of malaria infection (Pepys \& Baltz 1983). However, the role of CRP in malaria pathogenesis or protection is not well established and the majority of data available concerns $P$. falciparum infections in African populations. In Brazilian populations, possible roles for CRP and other inflammation markers were reported in severe vivax malaria patients (Andrade et al. 2010); otherwise, the literature lacks data for CRP levels in patients with uncomplicated $P$. falciparum and $P$. vivax malaria in Brazilian endemic areas. In our work, higher CRP levels were found in the plasma of $P$. vivaxinfected individuals compared to $P$. falciparum-infected

TABLE

Clinical and epidemiological characteristics of the studied population

\begin{tabular}{|c|c|c|c|c|}
\hline Variables & $\begin{array}{l}\text { Control } \\
(n=19)\end{array}$ & $\begin{array}{c}\text { Malaria } \\
(\mathrm{n}=71)\end{array}$ & $\begin{array}{c}\text { Plasmodium } \\
\text { vivax } \\
(\mathrm{n}=47)\end{array}$ & $\begin{array}{l}\text { Plasmodium } \\
\text { falciparum } \\
\quad(\mathrm{n}=24)\end{array}$ \\
\hline Male $\left[n^{\circ}(\%)\right]$ & $8(42.1)$ & $54(76)$ & $35(74.5)$ & $19(79.2)$ \\
\hline Age [median of years (IQ)] & $29(29-40)$ & $28(22-40)$ & $28(22-38)$ & $28.5(23-41)$ \\
\hline Years of residence in endemic area [median (IQ)] & $29(18-32)$ & $25(20-36)$ & $24(21-36)$ & $27(19-37)$ \\
\hline Previous malaria episodes [median (IQ)] & $1(0-3)$ & $3(1-10)$ & $3(1-8)$ & $4(2-10)$ \\
\hline Months since the last malaria episode [median (IQ)] & $60(20-180)$ & $11(2-34)$ & $10(2-24)$ & $13(2-102)$ \\
\hline Elapsed days since symptoms onset [median (IQ)] & NA & $3(2-10)$ & $3(2-7)$ & $3(2-10)$ \\
\hline \multicolumn{5}{|l|}{ Symptoms (frequency) $\left[\mathrm{n}^{\circ}(\%)\right]$} \\
\hline Fever & 0 & $61(85)$ & $39(83)$ & $22(91.7)$ \\
\hline Headache & 0 & $60(84)$ & $39(83)$ & $21(87.5)$ \\
\hline Myalgia & 0 & $52(73)$ & $32(68.1)$ & $20(83.3)$ \\
\hline Shiver & 0 & $52(73)$ & $31(66)$ & $21(87.5)$ \\
\hline Nausea & 0 & $39(69)$ & $23(48.9)$ & $16(66.7)$ \\
\hline Parasitaemia [parasites $(\mu \mathrm{L})]$ & - & 2.051 & 1.256 & 2.293 \\
\hline Median (IQ) & 0 & $(874-6.614)$ & $(697-5.222)$ & $(874-7.481)$ \\
\hline
\end{tabular}

IQ: interquartile range; NA: non-applicable. 
individuals, suggesting a more robust inflammatory profile for $P$. vivax infection in the studied population. Due to a number of conflicting publications, the roles of $\mathrm{CRP}$ and NO in the immune response to Plasmodium remain uncertain (Kremsner et al. 1996, Gyan et al. 2002, Awasthi et al. 2003, Clark \& Cowden 2003). NO, which is produced by various cells in the liver and peripheral blood, could serve as a defence against invading microorganisms and parasites (Ellis et al. 1998). In animal models, NO regulated by CD8 $\mathrm{T}$ cells can prevent the development of the exo-erythrocytic stage in the liver. The NO pathway may be a necessary component for the inhibition of sporozoite development and the elimination of infected hepatocytes (Seguin et al. 1994). It is not known whether the induction of $\mathrm{NO}$ activity is sufficient for protection against sporozoite development in the liver or necessary for CRP and/or other inflammatory mediators to induce pathogenic processes or protective responses against human malaria parasites.

In our cohort, the plasma levels of NO in the acute and convalescent phases were higher in P. falciparum patients than in controls and $P$. vivax patients. The presence of elevated $\mathrm{NO}$ in P. falciparum individuals was reported in uncomplicated and complicated $P$. falciparum malaria cases (el-Nashar et al. 2002, Gyan et al. 2002, Nahrevanian 2006, Yeo et al. 2007). Finally, we cannot rule out the possibility that genetic polymorphisms in the parasite and/or in the human genes encoding CRP (Israelsson et al. 2009, Giha et al. 2010, 2011) and NO (Kun et al. 2001, Hobbs et al. 2002, Levesque et al. 2010), which have been reported in different regions, could be responsible for the differences between the levels of these molecules in our population and those reported in other endemic areas.

In conclusion, our data indicate that individuals with uncomplicated $P$. vivax and $P$. falciparum infection presented similar white blood cell inflammatory profiles, with high band cell production and a considerable degree of thrombocytopaenia during the acute phase of infection. Higher CRP levels were detected in acute $P$. vivax infection, while higher NO levels were detected in acute and convalescent $P$. falciparum infections. Although changes in these mediators are not diagnostic of malaria infection, the haematological parameters associated with malaria infection, particularly the role of PLTs and band cells, require further investigation.

\section{REFERENCES}

Abbasi A, Butt N, Sheikh QH, Bhutto AR, Munir SM, Ahmed SM 2009. Clinical features, diagnostic techniques and management of dual dengue and malaria infection. J Coll Physicians Surg Pak 19: 25-29.

Akira S, Takeda K 2004. Toll-like receptor signalling. Nat Rev Immunol 4: 499-511.

Andrade BB, Reis-Filho A, Souza-Neto SM, Clarencio J, Camargo LM, Barral A, Barral-Netto M 2010. Severe Plasmodium vivax malaria exhibits marked inflammatory imbalance. Malar J 9: 13.

Appelberg R 2007. Neutrophils and intracellular pathogens: beyond phagocytosis and killing. Trends Microbiol 15: 87-92.

Armah HB, Wilson NO, Sarfo BY, Powell MD, Bond VC, Anderson W, Adjei AA, Gyasi RK, Tettey Y, Wiredu EK, Tongren JE, Udhayakumar V, Stiles JK 2007. Cerebrospinal fluid and serum biomarkers of cerebral malaria mortality in Ghanaian children. Malar J 6: 147.

Awasthi A, Kumar A, Upadhyay SN, Yamada T, Matsunaga Y 2003. Nitric oxide protects against chloroquine resistant Plasmodium yoelii nigeriensis parasites in vitro. Exp Parasitol 105: 184-191.

Brown J, Smalley ME 1981. Inhibition of the in vitro growth of Plasmodium falciparum by human polymorphonuclear neutrophil leucocytes. Clin Exp Immunol 46: 106-109.

Casals-Pascual C, Kai O, Newton CR, Peshu N, Roberts DJ 2006. Thrombocytopenia in falciparum malaria is associated with high concentrations of IL-10. Am J Trop Med Hyg 75: 434-436.

Clark IA, Cowden WB 2003. The pathophysiology of falciparum malaria. Pharmacol Ther 99: 221-260.

Conroy AL, Liles WC, Molyneux ME, Rogerson SJ, Kain KC 2011. Performance characteristics of combinations of host biomarkers to identify women with occult placental malaria: a case-control study from Malawi. PLoS ONE 6: e28540.

Corti A, Franzini M, Cianchetti S, Bergamini G, Lorenzini E, Melotti P, Paolicchi A, Paggiaro P, Pompella A 2012. Contribution by polymorphonucleate granulocytes to elevated gamma-glutamyltransferase in cystic fibrosis sputum. PLoS ONE 7: e34772.

Dong Q, Wright JR 1996. Expression of C-reactive protein by alveolar macrophages. J Immunol 156: 4815-4820.

Ellis G, Adatia I, Yazdanpanah M, Makela SK 1998. Nitrite and nitrate analyses: a clinical biochemistry perspective. Clin Biochem 31: $195-220$.

el-Nashar TM, el-Kholy HM, el-Shiety AG, Al-Zahaby AA 2002. Correlation of plasma levels of tumor necrosis factor, interleukin-6 and nitric oxide with the severity of human malaria. J Egypt Soc Parasitol 32: 525-535.

Erhart LM, Yingyuen K, Chuanak N, Buathong N, Laoboonchai A, Miller RS, Meshnick SR, Gasser Jr RA, Wongsrichanalai C 2004. Hematologic and clinical indices of malaria in a semi-immune population of western Thailand. Am J Trop Med Hyg 70: 8-14.

Giha HA, Nasr A, Ekstrom M, Israelsson E, Arambepola G, Arnot D, Theander TG, Troye-Blomberg M, Berzins K, Tornvall P, ElGhazali G 2010. Association of a single nucleotide polymorphism in the C-reactive protein gene (-286) with susceptibility to Plasmodium falciparum malaria. Mol Med 16: 27-33.

Giha HA, Nasr A, Iriemenam NC, Troye-Blomberg M, Berzins K, Pandey JP, Elghazali G 2011. Associations of multi-locus polymorphisms in an immune network with susceptibility to uncomplicated Plasmodium falciparum malaria in Daraweesh village, Eastern Sudan. Infect Genet Evol 11: 1674-1681.

Gillespie SH, Dow C, Raynes JG, Behrens RH, Chiodini PL, McAdam KP 1991. Measurement of acute phase proteins for assessing severity of Plasmodium falciparum malaria. J Clin Pathol 44: 228-231.

Gotschlich EC, Edelman GM 1967. Binding properties and specificity of C-reactive protein. Proc Natl Acad Sci USA 57: 706-712.

Graca-Souza AV, Arruda MA, de Freitas MS, Barja-Fidalgo C, Oliveira PL 2002. Neutrophil activation by heme: implications for inflammatory processes. Blood 99: 4160-4165.

Greve B, Lehman LG, Lell B, Luckner D, Schmidt-Ott R, Kremsner PG 1999. High oxygen radical production is associated with fast parasite clearance in children with Plasmodium falciparum malaria. J Infect Dis 179: 1584-1586.

Griffiths MJ, Shafi MJ, Popper SJ, Hemingway CA, Kortok MM, Wathen A, Rockett KA, Mott R, Levin M, Newton CR, Marsh K, Relman DA, Kwiatkowski DP 2005. Genomewide analysis of the host response to malaria in Kenyan children. J Infect Dis 191: 1599-1611. 
Gyan B, Kurtzhals JA, Akanmori BD, Ofori M, Goka BQ, Hviid L, Behr C 2002. Elevated levels of nitric oxide and low levels of haptoglobin are associated with severe malarial anaemia in African children. Acta Trop 83: 133-140.

Habeeb H, Ripper JR, Cohen A, Hinfey PB 2012. A case of imported severe Plasmodium falciparum malaria in the emergency department and the current role of exchange transfusion treatment. $J$ Emerg Med PMID:22609412.

Harpaz R, Edelman R, Wasserman SS, Levine MM, Davis JR, Sztein MB 1992. Serum cytokine profiles in experimental human malaria. Relationship to protection and disease course after challenge. J Clin Invest 90: 515-523.

Hobbs MR, Udhayakumar V, Levesque MC, Booth J, Roberts JM, Tkachuk AN, Pole A, Coon H, Kariuki S, Nahlen BL, Mwaikambo ED, Lal AL, Granger DL, Anstey NM, Weinberg JB 2002. A new NOS2 promoter polymorphism associated with increased nitric oxide production and protection from severe malaria in Tanzanian and Kenyan children. Lancet 360: 1468-1475.

Israelsson E, Ekstrom M, Nasr A, Dolo A, Kearsley S, Arambepola G, Homann MV, Maiga B, Doumbo OK, Elghazali G, Giha HA, Troye-Blomberg M, Berzins K, Tornvall P 2009. Marked differences in CRP genotype frequencies between the Fulani and sympatric ethnic groups in Africa. Malar J 8: 136.

Kharazmi A, Jepsen S 1984. Enhanced inhibition of in vitro multiplication of Plasmodium falciparum by stimulated human polymorphonuclear leucocytes. Clin Exp Immunol 57: 287-292.

Kremsner PG, Winkler S, Wildling E, Prada J, Bienzle U, Graninger W, Nussler AK 1996. High plasma levels of nitrogen oxides are associated with severe disease and correlate with rapid parasitological and clinical cure in Plasmodium falciparum malaria. Trans R Soc Trop Med Hyg 90: 44-47.

Kun JF, Mordmuller B, Perkins DJ, May J, Mercereau-Puijalon O, Alpers M, Weinberg JB, Kremsner PG 2001. Nitric oxide synthase 2(Lambarene) (G-954C), increased nitric oxide production, and protection against malaria. J Infect Dis 184: 330-336.

Lacerda MVG, Mourão MPG, Coelho HCC, Santos JB 2011. Thrombocytopenia in malaria: who cares? Mem Inst Oswaldo Cruz 106 (Suppl. I): 52-63.

Ladhani S, Lowe B, Cole AO, Kowuondo K, Newton CR 2002. Changes in white blood cells and platelets in children with falciparum malaria: relationship to disease outcome. Br J Haematol 119: 839-847.

Levesque MC, Hobbs MR, O'Loughlin CW, Chancellor JA, Chen Y, Tkachuk AN, Booth J, Patch KB, Allgood S, Pole AR, Fernandez CA, Mwaikambo ED, Mutabingwa TK, Fried M, Sorensen B, Duffy PE, Granger DL, Anstey NM, Weinberg JB 2010. Malaria severity and human nitric oxide synthase type 2 (NOS2) promoter haplotypes. Hum Genet 127: 163-182.

Maina RN, Walsh D, Gaddy C, Hongo G, Waitumbi J, Otieno L, Jones D, Ogutu BR 2010. Impact of Plasmodium falciparum infection on haematological parameters in children living in Western Kenya. Malar $J 9$ (Suppl. 3): S4.

Martelo OJ, Smoller M, Saladin TA 1969. Malaria in American soldiers. Arch Intern Med 123: 383-387.

McGuire W, D'Alessandro U, Olaleye BO, Thomson MC, Langerock P, Greenwood BM, Kwiatkowski D 1996. C-reactive protein and haptoglobin in the evaluation of a community-based malaria control programme. Trans R Soc Trop Med Hyg 90: 10-14.

McMorran BJ, Marshall VM, de Graaf C, Drysdale KE, Shabbar M, Smyth GK, Corbin JE, Alexander WS, Foote SJ 2009. Platelets kill intraerythrocytic malarial parasites and mediate survival to infection. Science 323: 797-800.

Mohammed AO, Elghazali G, Mohammed HB, Elbashir MI, Xu S, Berzins K, Venge P 2003. Human neutrophil lipocalin: a specific marker for neutrophil activation in severe Plasmodium falciparum malaria. Acta Trop 87: 279-285.

Mora-Jensen H, Jendholm J, Fossum A, Porse B, Borregaard N, Theilgaard-Monch K 2011. Technical advance: immunophenotypical characterization of human neutrophil differentiation. J Leukoc Biol 90: 629-634.

Nahrevanian H 2006. Immune effector mechanisms of the nitric oxide pathway in malaria: cytotoxicity versus cytoprotection. Braz J Infect Dis 10: 283-292.

Nahrevanian H. Dascombe MJ 2001. Nitric oxide and reactive nitrogen intermediates during lethal and nonlethal strains of murine malaria. Parasite Immunol 23: 491-501.

Nahrevanian H, Gholizadeh J, Farahmand M, Assmar M 2008. Patterns of co-association of C-reactive protein and nitric oxide in malaria in endemic areas of Iran. Mem Inst Oswaldo Cruz 103: 39-44.

Oliveira-Ferreira J, Lacerda MV, Brasil P, Ladislau JL, Tauil PL, Daniel-Ribeiro CT 2010. Malaria in Brazil: an overview. Malar J 9: 115.

Pepys MB, Baltz ML 1983. Acute phase proteins with special reference to C-reactive protein and related proteins (pentaxins) and serum amyloid A protein. Adv Immunol 34: 141-212.

Perrin LH, Mackey LJ, Miescher PA 1982. The hematology of malaria in man. Semin Hematol 19: 70-82.

Price RN, Simpson JA, Nosten F, Luxemburger C, Hkirjaroen L, ter Kuile F, Chongsuphajaisiddhi T, White NJ 2001. Factors contributing to anemia after uncomplicated falciparum malaria. $\mathrm{Am} J$ Trop Med Hyg 65: 614-622.

Richards MW, Behrens RH, Doherty JF 1998. Short report: hematologic changes in acute, imported Plasmodium falciparum malaria. Am J Trop Med Hyg 59: 859.

Rockett, KA, Awburn MM, Rockett EJ, Cowden WB, Clark IA 1994. Possible role of nitric oxide in malarial immunosuppression. Parasite Immunol 16: 243-249.

Rojanasthien S, Surakamolleart V, Boonpucknavig S, Isarangkura P 1992. Hematological and coagulation studies in malaria. $J$ Med Assoc Thai 75 (Suppl. I): 190-194.

Seguin MC, Klotz FW, Schneider I, Weier JP, Goodbary M, Slayter M, Raney JJ, Aniagolu JU, Green SJ 1994. Induction of nitric oxide synthase protects against malaria in mice exposed to irradiated Plasmodium berghei infected mosquitoes: involvement of interferon gamma and CD8+ T cells. J Exp Med 180: 353-358.

Snounou G, Viriyakosol S, Zhu XP, Jarra W, Pinheiro L, do Rosario VE, Thaithong S, Brown KN 1993. High sensitivity of detection of human malaria parasites by the use of nested polymerase chain reaction. Mol Biochem Parasitol 61: 315-320.

Taylor WR, Widjaja H, Basri H, Ohrt C, Taufik T, Tjitra E, Baso S, Fryauff D, Hoffman SL, Richie TL 2008. Changes in the total leukocyte and platelet counts in Papuan and non Papuan adults from northeast Papua infected with acute Plasmodium vivax or uncomplicated Plasmodium falciparum malaria. Malar J 7: 259.

Winters RA, Murray HW 1992. Malaria - the mime revisited: fifteen more years of experience at a New York City teaching hospital. Am J Med 93: 243-246.

Yeo TW, Lampah DA, Gitawati R, Tjitra E, Kenangalem E, McNeil YR, Darcy CJ, Granger DL, Weinberg JB, Lopansri BK, Price RN, Duffull SB, Celermajer DS, Anstey NM 2007. Impaired nitric oxide bioavailability and L-arginine reversible endothelial dysfunction in adults with falciparum malaria. J Exp Med 204: 2693-2704.

Zhu L, Chen G, Xia Q, Tang W, Huang Z, Wang M, Guo J, Yang X, Zhou Y 2010. Use of band cell percentage as an early predictor of death and ICU admission in severe acute pancreatitis. Hepatogastroenterology 57: 1543-1548. 